\title{
A Metamodel Simulation Based Optimisation Approach for the Tidal Turbine Location Problem
}

\author{
Eduardo González-Gorbeña Eisenmann (Corresponding author) \\ Dept. of Ocean Engineering, COPPE / Universidade Federal de Rio de Janeiro \\ Centro de Tecnologia, Bloco C, sala 203, Cidade Universitaria, Ilha do Fundao, CEP: \\ 21945-970, Rio de Janeiro, Brazil \\ Tel: 55-21-9843-3435Ｅ-mail: eduardogg@oceanica.ufrj.br
}

\begin{abstract}
Raad Yahya Qassim
Dept. of Ocean Engineering, COPPE / Universidade Federal de Rio de Janeiro

Centro de Tecnologia, Bloco C, sala 203, Cidade Universitaria, Ilha do Fundao, CEP:

21945-970, Rio de Janeiro, Brazil
\end{abstract}

Tel: 55-21-3938-8756 E-mail: qassim@peno.ufrj.br

\begin{abstract}
Paulo Cesar Colonna Rosman
Dept. of Ocean Engineering, COPPE / Universidade Federal de Rio de Janeiro

Centro de Tecnologia, Bloco C, sala 203, Cidade Universitaria, Ilha do Fundao, CEP:

21945-970, Rio de Janeiro, Brazil
\end{abstract}

Tel: 55-21-3938-8747Ｅ-mail: pccrosman@ufrj.br

Received: July 30, 2014 Accepted: September 23, $2014 \quad$ Published: January 1, 2015

doi:10.5296/ast.v3i1.6544 URL: http://dx.doi.org/10.5296/ast.v3i1.6544

\begin{abstract}
A metamodel simulation based optimisation approach for the tidal turbine location problem is introduced. The method comprises design of experiments, computational simulations, metamodel construction and formulation of a mathematical optimisation model. Sample plans with different number of data points are used to fit 2 nd and $3 \mathrm{rd}$ order polynomial as a function of two design parameters: longitudinal and lateral spacing, with a view to approximating the power output of tidal turbine farms with inline and staggered layouts, each
\end{abstract}


of them with a fixed number of turbines. The major advantage this method has, in comparison to those reported in the literature, is the capability to analyse different design parameter combinations that satisfy optimality criteria in reasonable computational time, while taking into account complex flow-turbine interactions.

Keywords: Marine and river hydrokinetic energy, Tidal turbines, Metamodel simulation based optimization, Computational fluid dynamics, Design of computer experiments 


\section{Introduction}

Tidal current energy, along with offshore wind energy, are considered to be the most promising renewable energy sources for large scale conversion to electrical power, so much so that it is expected that this pair of renewable energy sources will reach commercial viability within the next decade (Esteban \& Leary, 2012). The basis for the implementation of tidal currents and offshore wind is conceptually identical in that fluid kinetic energy is employed to move turbine rotors, and the resultant mechanical energy is converted to electrical power; furthermore, both of these energy sources depend for their successful exploitation on two major factors: turbine technology and geographical site (Gunn \& Stock-Williams, 2013; Myhr et al., 2014). On the other hand, there exists an important feature which distinguishes offshore wind from tidal currents, in so far as their predictability is concerned. Offshore wind, like onshore wind, is highly unpredictable, and consequently a sophisticated stochastic treatment is necessary to forecast the temporal variation of wind velocity at a given spatial position. As a result, the reliability of electrical power generation from tidal currents is substantially higher than that from offshore and onshore wind (Xu \& Zhuan, 2013).

Once a geographical site is identified as promising for tidal current energy extraction, it is necessary to determine the best set of turbine locations within the site, giving rise to what is referred to as the Turbine Location Problem (TLP), which arises as well in wind energy extraction at a promising geographical site. The main objective of the TLP is to minimise wake interactions between turbines to ensure maximum power output. However, there is an important difference between the cases of wind energy, both offshore and onshore, on the one hand, and tidal current energy on the other. In the wind version of the TLP, the placement of one or more turbines within the site does not significantly influence the fluid velocity field in the absence of turbines; consequently, the fluid velocity field is considered as input in the wind variant of the TLP. An extensive literature exists on the wind variant of the TLP; e.g., see (Castro-Mora et al., 2007; Kusiak \& Song, 2010; Geem \& Hong, 2013; Samorani, 2013; Turner et al., 2014). In contradistinction, the placement of one or more turbines in a promising site for tidal current energy extraction alters the fluid velocity field in relation to that in the absence of turbines. As a result, the fluid velocity field is itself part of the output of the solution of the tidal variant of the TLP. Thus, the fluid velocity field has to be determined simultaneously with the locations of the turbines. This facet makes the tidal variant of TLP significantly more complex to formulate and solve than its wind energy counterpart.

The Tidal Turbine Location Problem (TTLP), which is the focus of this paper, constitutes a new extension to the classical Facility Location Problem (FLP) in operations research, which possesses an extensive literature spanning several decades; for reviews of variants, mathematical models, and solution methods of the FLP, see (Aikens, 1985; Owen \& Daskin, 1998; ReVelle \& Eiselt, 2005; Şahin \& Süral, 2007; Melo et al., 2009; Farahani et al., 2010; Aras et al., 2012; Beltrán-Royo et al., 2012; Farahani et al., 2012; Terouhid et al., 2012; Drezner, 2013; Öncan, 2013; Stanimirović, 2013). There have been numerous extensions to and variants of the FLP reflecting the specific application environment under consideration. Examples of such applications are: public centre server allocation (Marianov et al., 2005), 
alarm location in noisy environments (Lee \& Kong, 2006), emergency medical service location (Jia et al., 2007), soft-capacitated facility location (Alfandari, 2007), humanitarian relief chain location (Balcik \& Beamon, 2008), competitive facility location (Beresnev \& Suslov, 2010), facility location under threat (Aksen \& Aras, 2012), subsea cluster manifold location (Wang et al., 2012), budget constrained facility location (Jin, 2012), and logistics hub location (Farahani et al., 2013).

In almost all reported research work on the TTLP, two approaches have been employed. In the first type of approach, highly simplified one dimensional tidal flow models are employed (Bryden \& Couch, 2007; Garrett \& Cummins, 2008; Vennell, 2010, 2011, 2012). In the second type of approach, more complex multidimensional tidal flow models are adopted (Lee et al., 2010; Divett et al., 2013; Malki et al., 2014). The simplified model approach possesses the appeal of simplicity; however, this approach cannot capture the complex nonlinear fluid flow interactions between turbines. In the second approach, more realistic models are employed; nevertheless, they are so computationally demanding that the whole design parameter space cannot be explored, and as a consequence, only a limited number of manually selected tidal turbine farm configurations are studied in the search for an optimal solution. Recently, a third approach has been studied (Funke et al., 2014), whereby a gradient - based optimisation method is developed to solve the TTLP for a given initial turbine array configuration. In the approach presented in (Funke et al., 2014), a functional (of the solution of the shallow water fluid flow partial differential equations and of the design parameters, which comprise the location of turbines) is optimised subject to constraints, which include the shallow water fluid flow partial differential equations. The approach of (Funke et al., 2014) possesses several strong points: sound mathematical basis, relatively fast computation time even for large turbine arrays, and simultaneous determination of the fluid velocity field and the location of turbines. However, it cannot allow for the choice of different turbine types at different locations as part of the output, as in such cases, the design parameter space includes discrete variables, reflecting the different turbine types, which is typical of equipment selection problems in operations research (Topal \& Ramazan, 2010; Yilmaz \& Dağderviren, 2011). The presence of discrete variables leads to non-smooth non-differentiable functions and this impedes the use of gradient-based methods, such as those employed in (Funke et al., 2014). This may be a serious limitation in practice, such as geographical sites with highly non-uniform bathymetry. In such cases, the economic viability of tidal energy extraction depends on the use of different turbine types at different points within the site, so as to ensure fluid depth - turbine size compatibility, and where the fluid velocity - turbine type choice itself needs to be determined simultaneously with the location of turbines. For such cases, a fourth type of approach is adopted in this paper, whereby, Simulation Based Optimisation (SBO) is used for the TTLP. For an extensive review of SBO; c.f. (Fang et al., 2005; Barton \& Meckesheimer, 2006; Chen et al., 2006; Mack et al., 2007; Levy \& Steinberg, 2010).

The rest of the paper is organised as follows. A general formulation of the TTLP is presented in Section 2. As this is computationally non-implementable, the SBO approach is described in Section 3, with a view to surmounting this hurdle. This is followed in Section 4, by the application of the SBO to a case study. The paper is concluded in Section 5, where the SBO 
approach is assessed, and extension of the SBO approach is presented.

\section{Problem Formulation}

The TTLP, as is the case with the FLP in general, may be formulated in one of two ways (Ozturk \& Norman, 2004; Klose \& Drexl, 2005; ReVelle \& Eiselt, 2005): continuous formulation, where a turbine may be located at any point in the spatial fluid field under consideration, or discrete formulation where a turbine may be located at a point which belongs to a finite set of candidate sites. The continuous formulation is superior to the discrete formulation as the solutions of the latter may be suboptimal to the former; however, solution methods of the discrete formulation are more efficient than its continuous counterpart, and it is for this reason that it is more commonly employed (Kuby, 2005). In Subsection 2.1, a discrete formulation is used to develop a mathematical model of the TLLP for a turbine array of a general configuration; however, the model so formulated is not computationally implementable for reasons which are explained therein. In order to overcome the barrier of the impossibility of computational implementation, a continuous formulation is utilised to formulate a mathematical model for one variant of the TLLP, whereby a turbine array is assumed to be one of two specific configurations: inline or staggered, each of them with a fixed number of turbines. The resulting model is computationally implemented employing a SBO procedure, which is described in Section 3.

\subsection{General Configuration Turbine Array}

In the spatial fluid field, let $\mathbf{G}=(\mathbf{V}, \mathbf{E})$ denote a graph with vertices $\mathbf{V}$ and edges $\mathbf{E} \subseteq \mathbf{V} \times \mathbf{V}$; furthermore, let the vertices $\mathbf{V}$ correspond to the set of locations where turbines can be located, and let the vertices $\mathbf{E}$ represent vertex pairs between which there exists a relationship, such as geometric proximity, due to turbine size, and hydrodynamic interference, due to turbine wakes. For a given turbine type, the region surrounding a vertex may be partitioned into three distinct regions. For a vertex v, these three regions are:

1. A region denoted as $\mathbf{R} \boldsymbol{v}$ where another turbine cannot be located due to geometric proximity.

2. A region denoted as $\mathbf{S} \boldsymbol{v}$ where another turbine cannot be located due to hydrodynamic interference.

3. A region where one or more turbines can be located.

Let $P t v$ denote the amount of power that would be generated if a turbine type $t$ is located at vertex $\mathrm{v} \in \mathbf{V}$, and let $X t v$ denote the $\{0,1\}$ binary variable which takes the value of 1 if a turbine type $t \in \mathbf{T}$ is located at the vertex $v$, and 0 otherwise. Let y denote a location vector within the spatial region in which the turbine array is to be placed. Then, the generic TTLP may be written as:

$$
\operatorname{maximise} \sum_{v \in \mathbf{V}} P_{t v} X_{t v}
$$


subject to:

$$
\begin{aligned}
& \text { if }\left(X_{t v}=1\right) \text { then }\left(X_{t v}=0\right) \quad t \in \mathbf{T}, \quad v \in \mathbf{R}_{v} \\
& \text { if }\left(X_{t v}=1\right) \text { then }\left(X_{t v}=0\right) \quad t \in \mathbf{T}, \quad v \in \mathbf{S}_{v} \\
& F_{t}\left(v, \mathbf{y}, X_{t v}\right)=0 \quad t \in \mathbf{T}, \quad v \in \mathbf{V} \\
& X_{t v} \in\{0,1\} \quad t \in \mathbf{T}, \quad v \in \mathbf{V}
\end{aligned}
$$

The objective function (1) depicts total power of the turbine array. The constraints (2) ensure a lower bound for the geometrical proximity for a turbine pair. The constraints (3) ensure a lower bound for the hydrodynamic interference for a turbine pair. The constraints (4) depict other constraints, such as that a turbine type is too close to the top surface and / or to the bottom bed of the region in which the turbine is to be located. The constraints (5) define the domain of the decision variables. As it stands, the optimisation model given by (1) - (5) is computationally non-implementable, in view of the fact that the power output of a turbine at a node, Ptv, which is a coefficient in the objective function (1), is a function of the fluid velocity at that node, which in turn depends on the presence or absence of a turbine, which is determined by the binary decision variable $X t v$. In other words, as the fluid velocity at a node is not part of input data, so is the power output, and therefore the objective function (1) is not computable. As stated in Section1, this is not the case in a wind turbine array, where the fluid velocity field is known a priori and constitutes part of the input data. In order to overcome this difficulty in tidal turbine array design, which is the focus of this paper, the approach of SBO is adopted in this work.

\section{Metamodel Based Simulation Optimisation Procedure}

In order to render the general optimisation model given by (1) - (5) suitable for computational implementation, an SBO approach is employed, considering a specific class of turbine arrays, which is characterised by a pair of continuous spatial parameters. One parameter defines the distance between two successive rows of turbines, and the other parameter defines the distance between adjacent turbines in the same row. Within this class of turbine arrays, two configurations are studied: inline and staggered, which have been studied in (Draper \& Nishino, 2014). A flow diagram summarising the Metamodel Based Simulation Optimisation (MBSO) procedure that is employed in this work is shown in Figure 1. 


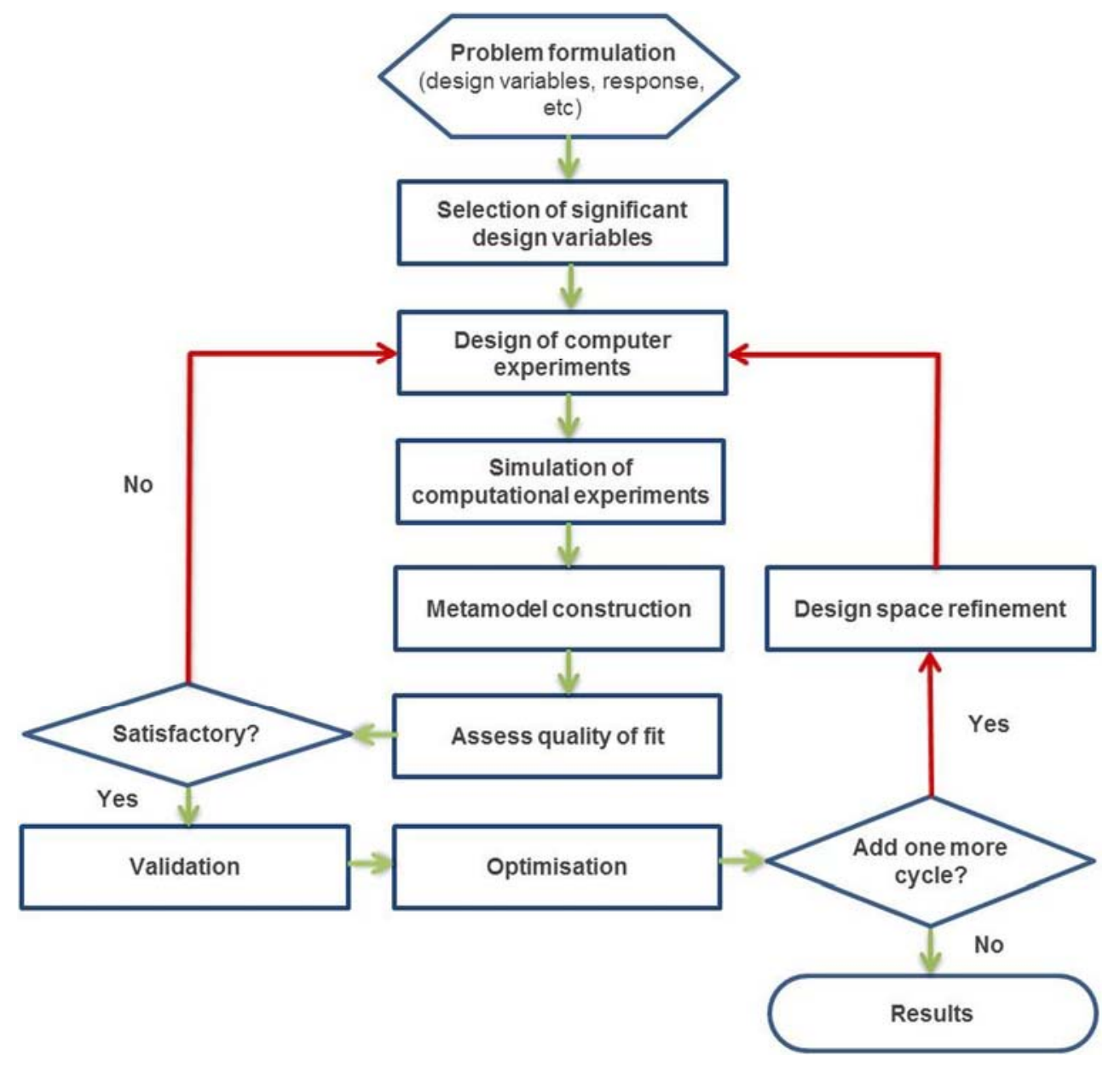

Figure 1. Metamodel-based simulation optimisation flow chart

The procedure consists of the following steps:

1. Definition of design variables and response function of the computational simulation. This is a key step. In some cases, identifying design variables and response are obvious, but sometimes they must be carefully selected to simplify the optimisation procedure.

2. Design of computer experiments. The objective of a sample plan is to reduce bias between expensive computer simulations and the approximated model with the minimum possible number of sample points. For this purpose, a design of computer experiments needs to provide unique relationships between design variables, as well as an adequate coverage of the input variable space. Various approaches exist to filling the available space and go from random designs to space-filling designs that seek some kind of optimality criteria (Simpson, 2001, Palmer \& Realff, 2002). A weakness of the latter approach is that for their construction, the number of sample points need to be defined a priori. Thus, if we need to increase the number of observed data it is necessary to create a new design to preserve the optimality criteria. This involves discarding expensive computer simulations, which translates in loss of time.

3. Simulation of deterministic computer experiments. Even though deterministic computer 
simulations replicate results for same values of input variables, there are some sensibility parameters, like domain discretization, that can influence results.

4. Construction of the metamodel. Results from the computer experiments are then used to fit a desired function, named metamodel, or model of the simulation model. There is a wide variety of metamodels available in the literature, each of them with its advantages and expenses. For a review in metamodel techniques is recommended the reading of Fang et al. (2005), Barton and Meckesheimer (2006) and Wang and Shan (2006).

5. Assessment of the metamodel. A general form to assess the quality of the fit is using the coefficient of determination, $R^{2}$, which is a measurement how well the approximated model fits the observed data, and it is defined by the following equation:

$$
R^{2}=\frac{\sum_{i}\left(\hat{y}_{i}-\bar{y}\right)^{2}}{\sum_{i}\left(y_{i}-\hat{y}_{i}\right)^{2}+\sum_{i}\left(\hat{y}_{i}-\bar{y}\right)^{2}}
$$

where, $\hat{y}_{i}$ represents the predicted response and $y_{i}$ the simulation result for the $\mathrm{i}$-th simulation, and $\bar{y}$ the mean of the observed data. Naturally, values of $R^{2}$ close to 1 denote a better fit. Forrester (2008) points out that values of $R^{2}>0.8$ implies surrogates with good predictive capabilities.

6. If satisfactory, go to step 7; otherwise, go to step 2.

7. Validation of the metamodel. Once the metamodel is fit, we need to verify its capacity to predict responses with data points not considered during the regression. For this purpose, two measurements are used: the Predicted Residual Sums of Squares (PRESS) and the maximum absolute error $(M A X)$, which are defined by:

$$
\begin{gathered}
\text { PRESS }=\sum_{i}\left(y_{i}-\hat{y}_{i,-i}\right)^{2} \\
M A X=\max \left|y_{i}-\hat{y}_{i}\right|
\end{gathered}
$$

8. If satisfactory, stop; otherwise, go to step 2.

9. Metamodel optimisation. Once a reliable surrogate model is obtained, it may be used to find a design that will meet the optimality criteria. A mathematical optimisation model has the form:

Maximise $f_{0}(\mathbf{x})$

Subject to: $\quad f_{i}(\mathbf{x}) \leq b_{i}, \quad i=1,2, \ldots, k$

where the vector $\mathbf{X}=\left\{x_{1}, x_{2}, \ldots, x_{n}\right\}$ is the set of design variables of the problem, the 


\section{Macrothink}

function $f_{0}: \mathbf{R}^{\mathrm{n}} \rightarrow \mathbf{R}$ is the objective function, the functions $f_{i}: \mathbf{R}^{\mathrm{n}} \rightarrow \mathbf{R}, i=1, \ldots, k$ are the (inequality) constraint functions, and the constants $b_{1}, \ldots, b_{\mathrm{m}}$ are the bounds in the constraints.

\section{Case Study}

São Marcos Bay, Maranhão State, in the Northeast of Brazil on the South Atlantic Ocean Continental Shelf, has been shown to be a highly promising geographical site for tidal energy conversion to electrical power (Qassim, 2011). This is the site which is the focus of the case study considered in this work. It is desirable to optimise layouts of two tidal farm configurations: inline and staggered. Both configurations have a fixed known number of turbines: 10 and 14 turbines for the inline and staggered configurations, respectively. The fluid flow field considered is an idealised rectangular channel with uniform bathymetry $(h=$ $30 \mathrm{~m}$ ), and with unbounded channel width and length. It is assumed that the water surface level undergoes a cyclical variation with a period of $12 \mathrm{~h}$ and with a maximum water surface elevation, $\zeta$, of $6 \mathrm{~m}$, generating a bi-directional flow with maximum velocity of $2.6 \mathrm{~m} / \mathrm{s}$ and flow velocities half of the time, $U_{50}$, of at least $1.5 \mathrm{~m} / \mathrm{s}$ during a moon cycle, for approximately 28 days. The fluid flow velocity is assumed to possess a cubic law profile as a function of water column height, $H=\zeta+h$ :

$$
U(H)=U_{50}\left(\frac{H}{12.8}\right)^{1 / 7}
$$

where $H$ is the water column height.

\subsection{Objective Function and Design Variable Set Selection}

The following design variables have been selected:

1. Unsteady and non-uniform flow at inlet.

2. Time variations in water surface elevation.

3. Turbine type.

4. Number of turbines for each configuration.

5. Rotor diameter of each turbine.

6. Vertical position of each turbine.

7. Longitudinal distance between turbines.

8. Lateral distance between turbines.

In order to reduce the number of design variables, the following simplifying assumptions are made:

1. Steady state and uniform fluid flow at inlet.

2. $U_{50}$ adopted as inlet fluid flow velocity. 
3. Water surface elevation is omitted, so water depth corresponds to that of the chart datum, $H=h=30 \mathrm{~m}$.

4. One type of tidal turbine is considered in the whole farm, this being horizontal axis turbines, which, at present the time, possess the highest technology readiness level (TRL) (SI-Ocean 2012). The generalisation for multiple turbine types is to be considered in future work.

5. A constant turbine diameter of $20 \mathrm{~m}$ is maintained in the whole farm, with rotor centrelines positioned at half the water depth. This diameter size and positioning ensures $5 \mathrm{~m}$ spans between rotor tips and bottom and surface boundaries, thus avoiding slower moving waters at the bottom and allowing clearance at the top for marine traffic or adverse loads from storm waves (Bahaj \& Myers, 2004; Fraenkel, 2010).

6. The number of turbines is fixed for each of the configurations. For the inline and staggered cases, the number of turbines is set at 10 and 14, respectively. To preserve symmetry with respect to the flow direction, both configurations have different numbers of devices. In the inline case, two rows are considered, each row possessing five turbines. In order to maintain symmetry and assuming bi -directional flow in the staggered case, three rows are considered, where the first and third rows have five turbines and the middle row has four turbines.

7. Longitudinal spacing and lateral spacing remain constant in each array layout.

The formulation of the objective function raises two questions: what represents the metamodel and which are the independent variables. In the corresponding wind energy optimisation problem, for a given wind free stream velocity which is determined with the aid of analytical models, as via the Jensen wake model (Jensen, 1983), the wind velocity at any turbine within the farm is known, and likewise its power production. In the MBSO approach for the TTLP results in a function which is dependent on the position of the other turbines in the farm. In other words, this is a function with $N T-1$ variables, where $N T$ is the number of turbines in the farm.

Taking into consideration the above assumptions, we consider only two variables $\mathbf{x}=\left\{x_{1}, x_{2}\right\}$; i.e., longitudinal and lateral spacing. Then, we can define the objective function to be depicted by the cubic function for the whole array, instead of at each turbine.

Considering physical and operational restrictions, the limits of each variable are set to:

$5 D \leq x_{1} \leq 30 D$ and $1 D \leq x_{2} \leq 4 D$

The lower bound of $5 D$ for the longitudinal spacing variable defines the end of the near wake (Harrison et al., 2010), a region of high turbulence that should be avoided for turbine placement to prevent fatigue loads (McCann, 2007, Thompsom et al., 2012). The upper bound of $30 D$ is considered adequate for wake recovery (Myers \& Bahaj, 2010). The lower limit of $1 D$ for the lateral spacing variable denotes a geometrical limit, while the upper limit of $4 D$ is chosen so as to minimise the influence of power production of adjacent turbines in a row (Turnock et al., 2011). 


\section{Macrothink}

\subsection{Design of Computer Experiments}

In order to define the computer model scenarios to be executed, a plan for design of experiments need to be selected. In the literature, there exist numerous statistical methods for conducting computer experiments, some of which obeying a design optimisation criteria (Santner et al., 2003; Chen et al., 2006; Johnson et al., 2008).

In this work, the optimisation criteria of Minimum Bias Latin Hypercube Design (MBLHD) (Palmer, 1998) is selected as an initial collection plan for sampling deterministic computer simulations. This collection plan represents a compromise between empirical model bias reduction and dispersion of the points within the input variable space. MBLHD has been compared with other sampling plan methods, resulting in each case in at least competitive performance, and in some cases in superior performance (Palmer \& Tsui, 2001).

As an empirical rule, the number of data collection points in a sampling plan should be around ten times the number of design variables; cf., Loeppky et al. (2009). Other authors (Palmer \& Realff, 2002) state that the number of sample points must be at least equal to or greater than the number of model parameter to be estimated. In this work, three sample plans are evaluated and their relative performance is assessed. Initially, a MBLHD for 2 design variables and 16 sampling points (Figure 2a) has been selected. Then, the size of this sampling plan has been increased to include new sample points so as to improve polynomial fitting with the variable space end and middle values, first with 4 new points (Figure 2b) subsequently with another 5 new points (Figure $2 \mathrm{c})$. The sample values $(u=1,2, \ldots, N)$ for each input variable $(i=1,2, \ldots, m)$ are normalised on the interval $[-1,1]$.
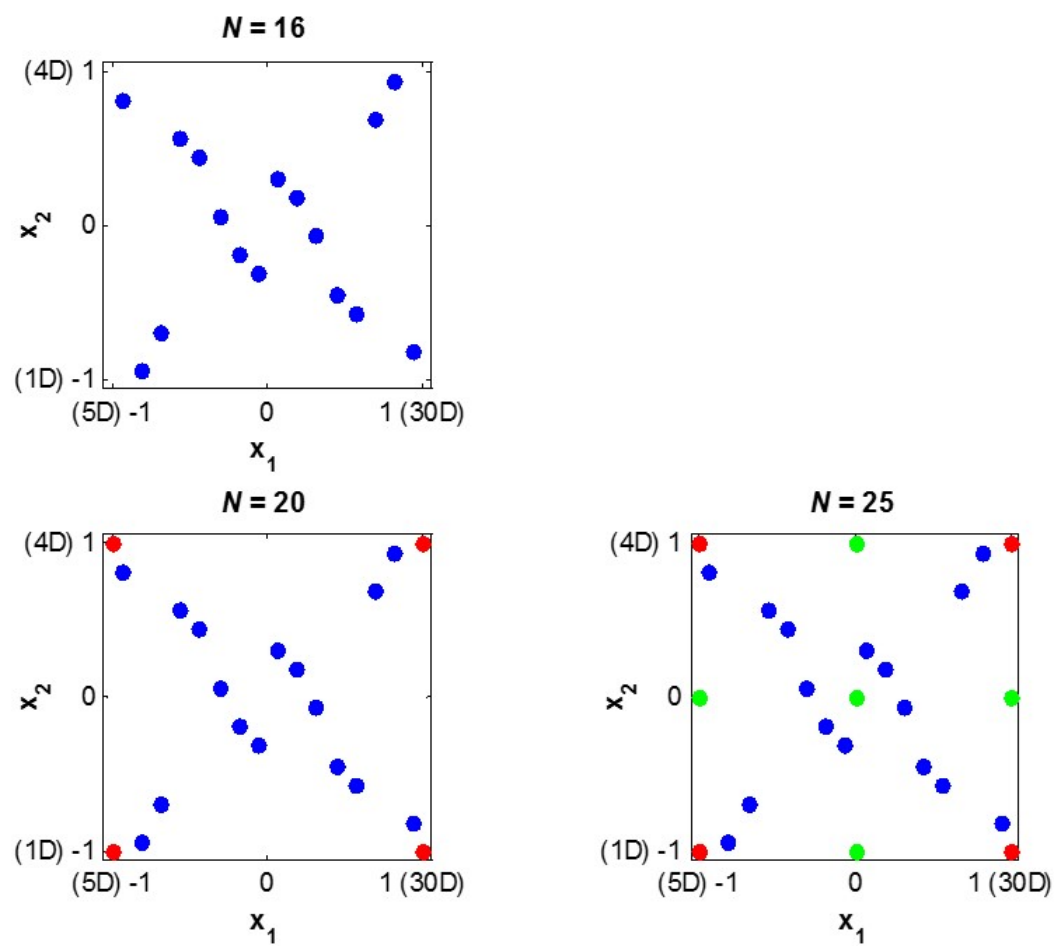

Figure 2. Sample plan designs

Notes: a) $\mathrm{N}=16, \mathrm{~b}) \mathrm{N}=20$ and c) $\mathrm{N}=25$. 


\subsection{Computer Simulation}

Computer simulation runs have been carried out using the CFD software ANSYS FLUENT (Ansys, 2012). Turbines are modelled as actuator disks, this being one of the simplest representations of a turbine, which provides reliable results with affordable computational expense (Sun, 2008; Bai et al., 2009, Turnock et al., 2011). In FLUENT, this is achieved using a porous-jump boundary condition (Ansys, 2012). Detailed information about the CFD simulations can be found in (Gorbeña, 2013).

Table 1 summarises results of power output for the whole farm obtained from the CFD simulations.

Table 1. Instantaneous power output results from CFD simulations of both layouts and for each array configuration

\begin{tabular}{|c|c|c|c|c|}
\hline \multirow{2}{*}{ Simulation } & \multirow{2}{*}{$x_{1}, D$} & \multirow{2}{*}{$x_{2}, D$} & \multirow{2}{*}{$\begin{array}{l}\text { Inline layout } \\
y_{\mathrm{i}}, \mathrm{MW}\end{array}$} & \multirow{2}{*}{$\begin{array}{l}\text { Staggered layout } \\
y_{\mathrm{i}}, \mathrm{MW}\end{array}$} \\
\hline & & & & \\
\hline 1 & 7.3 & 1.1 & 3.27 & 3.93 \\
\hline 2 & 29.2 & 1.3 & 3.66 & 4.40 \\
\hline 3 & 8.9 & 1.5 & 3.64 & 4.63 \\
\hline 4 & 24.5 & 1.7 & 3.87 & 4.80 \\
\hline 5 & 23.0 & 1.8 & 3.69 & 4.94 \\
\hline 6 & 16.7 & 2.0 & 3.78 & 5.15 \\
\hline 7 & 15.2 & 2.2 & 3.59 & 5.38 \\
\hline 8 & 21.4 & 2.4 & 3.80 & 5.37 \\
\hline 9 & 13.6 & 2.6 & 3.59 & 5.66 \\
\hline 10 & 19.8 & 2.8 & 3.69 & 5.44 \\
\hline 11 & 18.3 & 3.0 & 3.66 & 5.59 \\
\hline 12 & 12.0 & 3.2 & 3.51 & 5.59 \\
\hline 13 & 10.5 & 3.3 & 3.38 & 5.88 \\
\hline 14 & 26.1 & 3.5 & 3.57 & 5.58 \\
\hline 15 & 5.8 & 3.7 & 3.03 & 5.66 \\
\hline 16 & 27.7 & 3.9 & 3.39 & 5.54 \\
\hline 17 & 5.0 & 1.0 & 3.11 & 3.64 \\
\hline 18 & 30.0 & 1.0 & 3.54 & 4.07 \\
\hline 19 & 5.0 & 4.0 & 2.92 & 5.60 \\
\hline 20 & 30.0 & 4.0 & 3.61 & 5.54 \\
\hline 21 & 5.0 & 2.5 & 3.08 & 5.82 \\
\hline 22 & 17.5 & 1.0 & 3.53 & 3.97 \\
\hline 23 & 17.5 & 2.5 & 3.61 & 5.47 \\
\hline 24 & 17.5 & 4.0 & 3.54 & 5.53 \\
\hline 25 & 30.0 & 2.5 & 3.78 & 5.37 \\
\hline
\end{tabular}


Individual instantaneous power output was calculated using Eqs. (10) and (11), and flow velocities at each turbine rotor are obtained from the CFD simulations; i.e.,

$$
\begin{gathered}
P=\frac{1}{2} \rho C_{P} A_{T} U_{0}^{3} \\
U_{0}=\frac{U_{d}}{(1-a)}
\end{gathered}
$$

where, $\rho$ depicts sea water density taken to be $1,025 \mathrm{~kg} / \mathrm{m}^{3}, C_{\mathrm{P}}$ depicts the power coefficient, $A_{T}$ the cross section area of the turbine rotor, $U_{0}$ depicts the flow velocity incident on the turbine, and $U_{d}$ depicts the flow velocity at the rotor, and a is constant known as the induction factor. The power coefficient $C_{P}$ and the axial induction factor $a$ are interrelated in accordance with actuator disk theory. In this work, values of $C_{P}=16 / 27$ and $a=1 / 3$ are adopted in order to achieve the theoretical maximum power extractable according to Betz's Law (Betz, 1920); however, it is worth noting that in tidal turbines, the Betz upper bound may well be exceeded (Vennell, 2013).

When a hydrokinetic device interacts with fluid flow, it produces a reduction in the momentum of the downstream flow. The region affected is known as the wake. Fluid flow velocity in the wake region of a turbine gradually recovers downstream until it reaches a profile close to the incident flow velocity; cf. (Bahaj et al., 2007). The rate of recovery may be affected by several factors including turbine characteristics and proximity with other turbine devices, boundaries, and flow turbulence (Bahaj et al., 2012). When a turbine is placed next to another with a certain lateral spacing forming a row, flow accelerates within the gap formed between them, due to the diminution of the area orthogonal to the flow direction. If a turbine is placed in this gap but further downstream, it can take advantage of this accelerated flow, allowing for a decrease in longitudinal distance between successive rows. Having this in mind, it is reasonable to expect for the inline layout that the maximum power output occurs at an unknown lateral distance, $x_{2}$, and the highest longitudinal spacing; i.e., $x_{1}=30 D$, while for the staggered layout this would occur at $x_{1}=5 D$.

\subsection{Model Building and Validation}

After the sampling plans have been computationally implemented, the next step involves selecting an approximating functional form to use as a metamodel. As mentioned before, there are multiple candidates each with its advantages and limitations. In this work, low order polynomial model are employed because they can provide accurate predictions from small data sets, they are relatively easy to construct and, they have been widely used in engineering problems (Box \& Draper, 1987).

The polynomials used are second order, as in Eq. (12), and third order, as in Eq. (13)

$$
\hat{y}(\mathbf{x})=\hat{\beta}_{0}+\sum_{i=\mathbf{1}}^{m} \hat{\beta}_{i} x_{i}+\sum_{l=1}^{m} \hat{\beta}_{i i} x_{i}^{2}+\sum_{i=1}^{m-1} \sum_{j=i+1}^{m} \hat{\beta}_{i j} x_{i} x_{j}, \quad i=1,2
$$




$$
\begin{aligned}
\hat{y}(\mathbf{x})= & \hat{\beta}_{0}+\sum_{i=1}^{m} \hat{\beta}_{i} x_{i}+\sum_{l=1}^{m} \hat{\beta}_{i i} x_{i}^{?}+\sum_{i=1}^{m-1} \sum_{j=i+1}^{m} \hat{\beta}_{i j} x_{i} x_{j}+\ldots \\
& \ldots \text { । } \sum_{i=1}^{m-1} \sum_{j=i+1}^{m} \hat{\beta}_{i j} x_{i}^{2} x_{j} \mid \sum_{i=1}^{m-1} \sum_{j=i+1}^{m} \hat{\beta}_{i j} x_{i} x_{j}^{2} \text { । } \sum_{l=1}^{m} \hat{\beta}_{i i} x_{i}^{3}, \quad i=1,2
\end{aligned}
$$

Polynomial parameters, $\hat{\beta}_{i}$, are calculated using the least squares method; i.e.,

$$
\sum_{i=1}^{N}\left\{y_{i}-\sum_{j=0}^{L} B_{j}(\mathbf{x}) \beta_{j}\right\}^{2}=\|\mathbf{y}-\mathbf{B} \boldsymbol{\beta}\|^{2}
$$

For each of the sample plans and layouts, results for metamodel fitting are summarised in Table 2.

Table 2. Coefficient of determination for each layout and metamodel

\begin{tabular}{llll}
\hline \multirow{2}{*}{$\boldsymbol{N}$} & Metamodel & $\boldsymbol{R}^{\mathbf{2}}$ & \\
\cline { 3 - 4 } & & Inline & Staggered \\
\hline \multirow{2}{*}{16} & $2^{\text {nd }}$ order & 0.8995 & 0.9747 \\
& $3^{\text {rd }}$ order & 0.9130 & 0.9882 \\
\multirow{2}{*}{20} & $2^{\text {nd }}$ order & 0.9039 & 0.9806 \\
& $3^{\text {rd }}$ order & 0.9401 & 0.9929 \\
& $2^{\text {nd }}$ order & 0.8812 & 0.9727 \\
& $3^{\text {rd }}$ order & 0.9342 & 0.9921 \\
\hline
\end{tabular}

As expected, the cubic polynomial results in a better fit of the sample data than the quadratic polynomial. In both polynomials, the fit of data collected is better for the staggered layout than for its inline counterpart.

Table 3 summarises results obtained from the validation process, where the second order metamodel is found to be superior for sample plans with less data points than the third order polynomial. Polynomials of high order tend to be unstable when fitted using small sample plans. This is evident in Figure 3, where the MAX criteria doubles for the cubic polynomial and $N=16$. As the number of sample points increases, the maximum differences between the simulator and the predicted models tend to decrease and converge to a specific value for both metamodels. 
Table 3. Configurations that maximise power extraction

\begin{tabular}{|c|c|c|c|c|c|c|}
\hline \multirow{2}{*}{$\mathbf{N}$} & \multirow{2}{*}{ Predicted points } & \multirow{2}{*}{ Layout } & \multicolumn{2}{|c|}{$2^{\text {nd }}$ order polynomial } & \multicolumn{2}{|c|}{$3^{\text {rd }}$ order polynomial } \\
\hline & & & PRESS & MAX, MW & PRESS & MAX, MW \\
\hline \multirow{2}{*}{16} & \multirow{2}{*}{9} & Inline & 0.6486 & 0.45 & 1.4181 & 0.81 \\
\hline & & Staggered & 0.3325 & 0.33 & 0.6885 & 0.65 \\
\hline \multirow{2}{*}{20} & \multirow{2}{*}{9} & Inline & 0.6215 & 0.43 & 0.8963 & 0.47 \\
\hline & & Staggered & 0.1241 & 0.16 & 0.1907 & 0.25 \\
\hline \multirow{2}{*}{25} & \multirow{2}{*}{9} & Inline & 0.1920 & 0.30 & 0.0437 & 0.14 \\
\hline & & Staggered & 0.1511 & 0.21 & 0.2044 & 0.24 \\
\hline
\end{tabular}
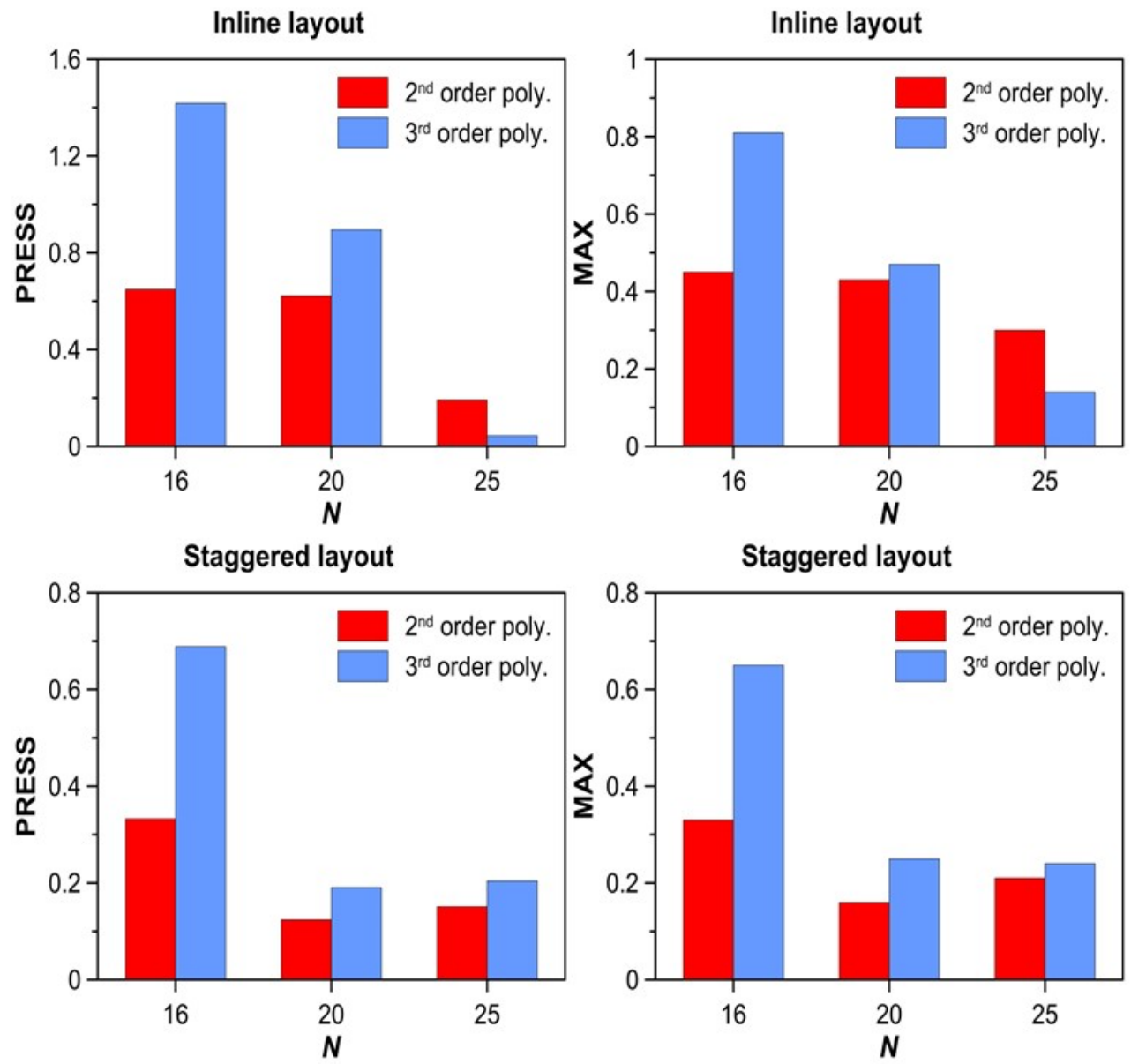

Figure 3. Bar graph of PRESS and MAX results for each layout and metamodel

The response surfaces for both layouts and metamodels are illustrated in Figure 4 for the sample plan with $N=25$. 

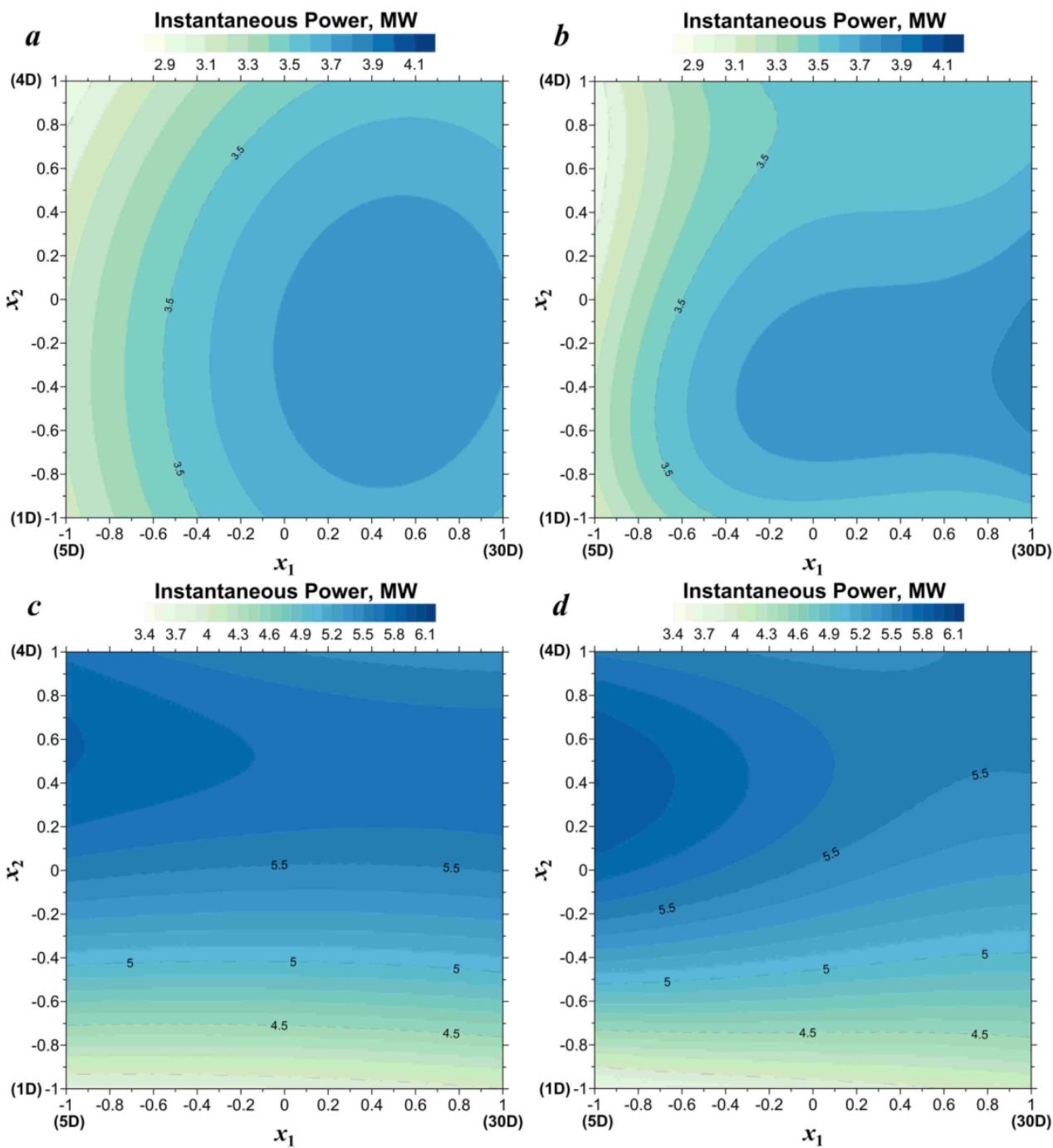

Figure 4. Response surfaces for both layouts

Notes: a) inline quadratic; b) inline cubic; c) staggered quadratic; and d) staggered cubic.

\subsection{Optimisation}

Once a valid metamodel is built, the mathematical optimisation model can be formulated. The optimisation model that is developed comprises geometric and hydrodynamic interference constraints. The metamodels used in the optimisation step correspond to those obtained for the sample plans with $N=25$. In order to compare results, both second order and third order polynomials are used for each configuration; i.e., inline and staggered.

\section{Objective function:}

$$
\text { Maximise } \quad \text { Power }=\hat{y}\left(x_{1}, x_{2}\right)
$$

- Inline objective functions:

$2^{\text {nd }}$ order polynomial: 


$$
\hat{y}(\mathbf{x})=2.6209+0.0036 x_{1}+0.0138 x_{2}-0.0002 x_{2}^{2}
$$

$3^{\text {rd }}$ order polynomial:

$$
\hat{y}(\mathbf{x})=1.7544+0.0072 x_{1}+0.0608 x_{1} \cdot x_{2}+0.0001 x_{2}^{2}-0.0014 x_{1}^{2} \cdot x_{2} ;
$$

- Staggered objective functions:

$2^{\text {nd }}$ order polynomial:

$$
\hat{y}(\mathbf{x})=1.8088+0.1199 x_{2}-0.0009 x_{2}^{2}
$$

$3^{\text {rd }}$ order polynomial:

$$
\hat{y}(\mathbf{x})=0.1908+0.005 x_{1}+0.2073 x_{2}-0.0002 x_{1} \cdot x_{2}-0.0022 x_{2}^{2} ;
$$

Subject to:

$$
\begin{gathered}
5 D \leq x_{1} \leq 30 D \\
1 D \leq x_{2} \leq 4 D \\
(N T R 1-1) x_{2} \leq 16 D \\
N T R 1=5 \\
(N F-1) x_{1} \leq 30 D^{*} \\
N F=2 *
\end{gathered}
$$

* Constrains (24) and (25) change for the staggered layout:

$$
\begin{gathered}
(N F-1) x_{1} \leq 60 D \\
N F=3
\end{gathered}
$$

Equations (16) - (19) represent the various objective functions depicting power output for the two layouts and the two polynomials.

- Constraints (20) and (21) express the domains of applicability of each of the design variables,

- Constraints (22) and (24) limits the size of the farm,

- Constraint (23) specifies the number of turbines in the first row, NTR1, and 
- Constraint (25) defines the number of rows, $N F$.

Optimisation results obtained are summarised inTable 4.

Table 4. Configurations that maximise power extraction

\begin{tabular}{llllllllll}
\hline \multirow{2}{*}{$\boldsymbol{N}$} & \multirow{2}{*}{ Metamodel } & \multicolumn{1}{c}{ Inline } & \multicolumn{10}{c}{ Staggered } \\
\cline { 3 - 10 } & & $\boldsymbol{x}_{\mathbf{1}}, \boldsymbol{D}$ & $\boldsymbol{x}_{\mathbf{2}}, \boldsymbol{D}$ & $\hat{\boldsymbol{y}}_{\boldsymbol{i}}, \mathbf{M W}$ & $\boldsymbol{y}_{\mathbf{i}}, \mathbf{M W}$ & $\boldsymbol{x}_{\mathbf{1}}, \boldsymbol{D}$ & $\boldsymbol{x}_{\mathbf{2}}, \boldsymbol{D}$ & $\hat{\boldsymbol{y}}_{\boldsymbol{i}}, \mathbf{M W}$ & $\boldsymbol{y}_{\mathbf{i}}, \mathbf{M W}$ \\
\hline \multirow{2}{*}{25} & $2^{\text {nd }}$ order poly. & 23.75 & 2.20 & 3.77 & 3.87 & 5.00 & 3.35 & 5.81 & 5.64 \\
& $3^{\text {rd }}$ order poly. & 30.00 & 2.00 & 3.85 & 3.91 & 5.00 & 3.10 & 5.90 & 5.71 \\
\hline
\end{tabular}

The results for the inline layout and $N=25$ show a discrepancy between the two metamodels of 6.25 diameters, $D$, and $0.20 \mathrm{D}$ for the longitudinal and lateral spacing design variables, respectively. As mentioned above, further downstream in the turbine wake, flow velocities are expected to increase, and therefore power output of the subsequent turbine also increases. The third order polynomial provides the expected maximum result for $x_{1}$ at $30 D$, due to the fact that for greater distances downstream of the turbines, the wake has greater capability to recover. The difference is associated to the flat region existent for longitudinal spacings greater than $12.5 \mathrm{D}$, visible in Figure $4 \mathrm{a}$, where the second order model cannot capture the small variability $(0.04 \mathrm{MW})$ of the CFD simulations in this region. On the other hand, the results of the staggered layout are consistent for both models, providing longitudinal distance results in accordance to what is expected. In the staggered layout, for a certain lateral distance, the minimum longitudinal distance of $5 D$ will ensure maximum power output. As a general remark, the predicted results for the inline case tend to sub-estimate the outputs of the simulations, while for the staggered case are overestimated.

\section{Conclusions}

In order to provide an appropriate model formulation and solution for the problem of layout optimisation of tidal turbine arrays, the use of the metamodel approach is presented for simulation based design optimisation. The methodology, considering problem formulation, data collection, metamodel construction and optimisation issues has been discussed.

Regarding problem formulation, the key issues have been identified with a view to defining the objective function and identifying significant design variables in order to maximise power extraction.

Three important aspects have been confirmed as goals for data collection plans: uniqueness of each data point, distribution of data points over the entire input variable domain, and reduction of metamodel bias. Fitting results with sample plans with different number of data points have been compared. The limitations of designs of experiments with optimisation criteria and fixed number of data points have been identified, when used to sample expensive computational simulations.

Three-dimensional CFD simulations of inline and staggered tidal farm configurations have been modelled as idealised rectangular tidal channels. The use of computational simulation 
allows the characterisation of complex flow-turbine interactions that is necessary to solve the TTLP.

The second order and third order polynomial models have been used to build metamodels to predict power output of a farm as a function of two design variables: longitudinal and lateral spacings. Aspects related to the assessment of the quality the validation of the metamodels have been studied. Both polynomials appropriately represent the simulation model when built with sufficient data points.

In the optimisation step of the MSBO procedure, geometric and hydrodynamic interference constraints are considered in the case study, noting that other constraints may be added, if and when, necessary to define other facets that may arise to support decision making on changes in the array configuration design.

The major extension of the work reported in this paper is to employ the SBO approach to more complex problems that arise in practice. Normally, a geographical site that is identified as promising for tidal current energy extraction, possesses characteristics in terms of non-uniform bathymetry and three-dimensional fluid velocity distribution, that a multiplicity of turbine types is required in order to ensure the economic viability of tidal current energy extraction. As a result, the TTLP encompasses several turbine types, with each of which is associated a set of discrete design parameters, such as rotor number and diameter, leading to the consideration of discrete design parameters in the TTLP. This aspect, which is not considered in the work reported in this paper, constitutes a rich challenge for the formulation and solution of an appropriate mathematical model for the TTLP.

\section{Acknowledgement}

The corresponding author wish to acknowledge the Ph.D. scholarship provided by the funding agencies: Federal Agency for Support and Evaluation of Graduate Education of Brazil (CAPES) and the Foundation for Supporting Research in the State of Rio de Janeiro (FAPERJ).

\section{References}

Aikens, C. H. (1985). Facility location models for distribution planning. Eur J Oper Res, 22(3), 263-279. http://dx.doi.org/10.1016/0377-2217(85)90246-2

Aksen, D., \& Aras, N. (2012). Abilevel fixed charge location model for facilities under imminent attack. Comp Oper Res, 39(7), 1364-1381. http://dx.doi.org/10.1016/j.cor.2011.08.006

Alfandari, L. (2007). Improved approximation of the general soft-capacitated facility location problem. RAIRO-Opt Res, 41(1), 83-93.

ANSYS Inc. (2012). ANSYS FLUENT User's Guide. Release 14.5, USA.

Aras, N., Altınel, İ. K., \& Orbay, M. (2007). New heuristic methods for the capacitated multi-facility Weber problem. Nav Res Log, 54(1), 21-32. http://dx.doi.org/10.1007/s00170-013-5114-7 
Bahaj, A. S., \& Myers, L. (2004). Analytical estimates of the energy yield potential from the Alderney Race (Channel Islands) using marine current energy converters. Renew Ener, 29(12), 1931-1945. http://dx.doi.org/10.1016/j.renene.2004.02.013

Bahaj, A. S., Myers, L. E., Rawlinson-Smith, R., \& Thomson, M. (2012). The effect of boundary proximity upon the wake structure of horizontal axis marine current turbines. OffshMech Arct Eng, 134(2), 1-8. http://dx.doi.org/10.1115/1.4004523

Bahaj, A. S., Myers, L. E., Thomson, M. D., \& Jorge, N. (2007). Characterising the wake of horizontal axis marine current turbines. Proc 7th EWTEC. http://dx.doi.org/10.1115/1.4004523

Bai, L., Spencer, R. G., \& Dudziak, G. (2009). Investigation of the influence of array arrangement and pacing on tidal energy converter (tec) performance using a 3-dimensional cfd model. Proc 8th Eur Wave Tidal Energ Conf, pp 654-660, Uppsala, Sweden.

Balcik, B., \& Beamon, B. M. (2008). Facility location in humanitarian relief. Int J Log, 11(2), 101-121. http://dx.doi.org/10.1080/13675560701561789

Barton, R. R., \& Meckesheimer, M. (2006). Metamodel-based simulation optimization. HandbOper Res Manag Sci, 13, 535-574. http://dx.doi.org/10.1016/S0927-0507(06)13018-2

Beltrán-Royo, C., Vial, J. P., \& Alonso-Ayuso, A. (2012). Semi-Lagrangian relaxation applied to the uncapacitated facility location problem. Comp Optim Appl, 51(1), 87-409. http://dx.doi.org/10.1007/s10589-010-9338-2

Beresnev, V. L., \& Suslov, V. I. (2010). A mathematical model of market competition. J Appl Ind Math, 4(2), 147-157. http://dx.doi.org/10.1134/S199047891002002X

Betz, A. (1920). Das Maximum der theoretischmoglichen Ausnutzung des Windesdurch Windmotoren. Zeitschriftfür das gesamte Turbinenwesen, 26, 307-309.

Box, E. P., \& Draper, N. R. (1987). Empirical model building and response surfaces. NewYork: Wiley.

Bryden, I. G., \& Couch, S. J. (2007). How much energy can be extracted from moving water with a free surface: A question of importance in the field of tidal current energy?. Renew Energ, 32(11), 1961-1966. http://dx.doi.org/10.1016/j.renene.2006.11.006

Castro-Mora, J., Calero-Barón, J. M., Riquelme-Santos, J. M., \& Burgos-Payán, M. (2007). An evolutive algorithm for wind farm optimal design. Neurocomputing, 70(16), 2651-2658. http://dx.doi.org/10.1016/j.neucom.2006.05.017

Chen, V. C., Tsui, K. L., Barton, R. R., \& Meckesheimer, M. (2006). A review on design, modeling and applications of computer experiments. IIE Trans, 38(4), 273-291. http://dx.doi.org/10.1007/s10182-010-0147-9

Divett, T., Vennell, R., \& Stevens, C. (2013). Optimization of multiple turbine arrays in a channel with tidally reversing flow by numerical modelling with adaptive mesh. Phil Trans $R$ Soc A: Math, PhysEnginSci, 371(1985), 20120251. http://dx.doi.org/10.1098/rsta.2012.0251 
Draper, S., \& Nishino, T. (2014). Centred and staggered arrangements of tidal turbines. $J$ Fluid Mech, 739, 72-93. http://dx.doi.org/10.1017/jfm.2013.593

Drezner, Z. (2013). Solving planar location problems by global optimization. Log Res, 6(1), 17-23. http://dx.doi.org/10.1007/s12159-012-0093-x

Esteban, M., \& Leary, D. (2012). Current developments and future prospects of offshore wind and ocean energy. Appl Energ, 90, 128-136. http://dx.doi.org/10.1016/j.apenergy.2011.06.011

Fang, K. T., Li, R., \& Sudjianto, A. (2005). Design and modeling for computer experiments. Chapman and Hall CRC Press.

Farahani, R. Z., Asgari, N., Heidari, N., Hosseininia, M., \& Goh, M. (2012). Covering problems in facility location: A review. Comp Ind Eng, 62(1), 368-407. http://dx.doi.org/10.1016/j.cie.2011.08.020

Farahani, R. Z., Hekmatfar, M., Arabani, A. B., \& Nikbakhsh, E. (2013). Hub location problems: A review of models, classification, solution techniques, and applications. Comp Ind Eng, 64(4),1096-1109. http://dx.doi.org/10.1016/j.cie.2013.01.012

Farahani, R. Z., SteadieSeifi, M., \& Asgari, N. (2010). Multiple criteria facility location problems: A survey. Appl Math Model, 34(7), 1689-1709. http://dx.doi.org/10.1016/j.apm.2009.10.005

Forrester, A., Sobester, A., \& Keane, A. (2008). Engineering design via surrogate modelling: a practical guide. John Wiley \& Sons.

Fraenkel, P. (2010). Practical tidal turbine design considerations: a review of technical alternatives and key design decisions leading to the development of the SeaGen 1.2 MW tidal turbine. Proc Ocean Power Fluid Mach Semin, London.

Funke, S. W., Farrell, P. E., \& Piggott, M. D. (2014). Tidal turbine array optimisation using the adjoint approach. Renew Energ, 63, 658-673. http://dx.doi.org/10.1016/j.renene.2013.09.031

Garrett, C., \& Cummins, P. (2008) Limits to tidal current power. Renew Energ, 33(11), 2485-2490. http://dx.doi.org/10.1016/j.renene.2008.02.009

Geem, Z. W., \& Hong, J. (2013). Improved Formulation for the Optimization of Wind Turbine Placement in a Wind Farm. Math. Probl Eng. http://dx.doi.org/10.1155/2013/481364

Gorbeña, E. G. (2013). Um modelo de otimização matemático para a geração de energia elétrica a partir de correntes hidrodinâmicas. $\mathrm{PhD}$ Thesis COPPE/UFRJ, Rio de Janeiro, RJ, Brazil

Portuguese). http://www.oceanica.ufrj.br/intranet/teses/2013_Doutorando_Eduardo_Gonzalez_Gorbena_E isenmann.pdf

Gunn, K., \& Stock-Williams, C. (2013). On validating numerical hydrodynamic models of complex tidal flow. Int J Mar Energ, 3, 82-97. http://dx.doi.org/10.1016/j.ijome.2013.11.013 
Harrison, M. E., Batten, W. M. J., Myers, L. E., \& Bahaj, A. S. (2010). Comparison between CFD simulations and experiments for predicting the far wake of horizontal axis tidal turbines. IET Renew Power Gener, 4(6), 613-627. http://dx.doi.org/10.1049/iet-rpg.2009.0193

Jensen, N. O. (1983). A note on wind turbine interaction. Riso-M-2411 Risoe Nat Lab, Roskilde, Denmark, 16.

Jia, H., Ordóñez, F., \& Dessouky, M. (2007). A modeling framework for facility location of medical services for large-scale emergencies. IIE Trans, 39(1), 41-55. http://dx.doi.org/10.1080/07408170500539113

Jin, H. W. (2012). A study on the budget constrained facility location model considering inventory management cost. RAIRO-Oper Res, 46(2), 107-123. http://dx.doi.org/10.1051/ro/2012011

Johnson, R., Jones, B., Fowler, J., \& Montgomery, D. (2008). Comparing designs forcomputer simulation experiments. Winter Simul Conf, 463-470.

Klose, A., \& Drexl, A. (2005). Facility location models for distribution system design. Eur J Oper Res, 162, 4-29. http://dx.doi.org/10.1016/j.ejor.2003.10.031

Kuby, M., Lim, S., \& Upchurch, C. (2005). Dispersion of nodes added to a network. Geographical Analysis, 37(4), 383-409. http://dx.doi.org/10.1111/j.0016-7363.2005.03704002.x

Kusiak, A., \& Song, Z. (2010). Design of wind farm layout for maximum wind energy capture. Renew Energ, 35(3), 685-694. http://dx.doi.org/10.1016/j.renene.2009.08.019

Lee, J. S., \& Kong, D. (2006). Investigation of hearing protection effects in an extreme noise environment with an alarm location problem. Int $J$ Ind Ergon, 36(8), 685-693. http://dx.doi.org/10.1016/j.ergon.2006.04.008

Lee, S. H., Jang, K., Lee, J., \& Hur, N. (2010). A numerical study for the optimal arrangement of ocean current turbine generators in the ocean current power parks. Curr Appl Phys, 10(2), S137-S141. http://dx.doi.org/10.1016/j.cap.2009.11.018

Levy, S., \& Steinberg, D. M. (2010). Computer experiments: A review. AStAAdv Stat Anal, 94(4), 311-324. http://dx.doi.org/10.1007/s10182-010-0147-9

Loeppky, J. L., Sacks, J., \& Welch, W. J. (2009). Choosing the sample size of a computer $\begin{array}{llll}\text { experiment: A } & \text { guide. } & \text { Technometrics, }\end{array}$ http://dx.doi.org/10.1198/TECH.2009.08040

Mack, Y., Goel, T., Shyy, W., \& Haftka, R. T. (2007). Surrogate Model-based Optimization Framework: A Case Study in Aerospace Design. EvolComputDyn Uncertain Environ, Ed S Yang, YS Ong, Y Jin, Springer Kluwer Academic Press 51, 323-342. http://dx.doi.org/10.1007/978-3-540-49774-5_14

Malki, R., Masters, I., Williams, A. J., \& Croft, T. N. (2014). Planning tidal stream turbine array layouts using a coupled blade element -computational fluid dynamics model. Renew 
Ener, 63, 46-54. http://dx.doi.org/10.1016/j.renene.2013.08.039

Marianov, V., Rios, M., \& Barros, F. J. (2005). Allocating servers to facilities, when demand is elastic to travel and waiting times. RAIRO-Opt Res, 39(3), 143-162. http://dx.doi.org/10.1051/ro:2006002

McCann, G. N. (2007). Tidal current turbine fatigue loading sensitivity to waves and turbulence - a parametric study. Proc 7th Eur Wave Tidal EnergConf, EWTEC, Porto, Portugal.

Melo, M. T., Nickel, S., \& Saldanha-Da-Gama, F. (2009). Facility location and supply chain management-A review. Eur $J$ Oper Res, 196(2), 401-412. http://dx.doi.org/10.1016/j.ejor.2008.05.007

Myers, L. E., \& Bahaj, A. S. (2010). Experimental analysis of the flow field around horizontal axis tidal turbines by use of scale mesh disk rotor simulators. Ocean Eng, 37, 218-227. http://dx.doi.org10.1016/j.oceaneng.2009.11.004

Myhr, A., Bjerkseter, C., Ågotnes, A., \& Nygaard, T. A. (2014). Levelised cost of energy for offshore floating wind turbines in a life cycle perspective. Renew Energ, 66, 714-728. http://dx.doi.org10.1016/j.renene.2014.01.017

Öncan, T. (2013). Heuristics for the single source capacitated multi-facility Weber problem. Comp Ind Eng, 64(4), 959-971. http://dx.doi.org10.1016/10.1016/j.cie.2013.01.005

Owen, S. H., \& Daskin, M. S. (1998). Strategic facility location: A review. Eur J Oper Res, 111(3), 423-447. http://dx.doi.org10.1016/10.1016/S0377-2217(98)00186-6

Ozturk, U. A., \& Norman, B. A. (2004). Heuristic methods for wind energy conversion systems positioning. Elect PowSysts Res, 70, 179-185. http://dx.doi.org10.1016/10.1016/j.epsr.2003.12.006

Palmer, K. (1998). Data collection plans and meta models for chemical process flowsheet simulators. PhD thesis, School of Industrial and Systems Engineering, Georgia Institute of Technology, Atlanta, GA. http://hdl.handle.net/1853/24511

Palmer, K., \& Realff, M. (2002). Metamodeling approach to optimization of steady-state flowsheet simulations: Model generation. Chem Eng Res Des, 80(7), 760-772. http://dx.doi.org10.1016/10.1205/026387602320776830

Palmer, K., \& Tsui, K. L. (2001). A minimum bias Latin hypercube design. IIE Trans, 33(9), 793-808.

Qassim, R. Y. (2011). Optimisation of systems for the extraction of energy from tidal currents. Technical Report Inter-American Development Bank Contract ATN/MC-11513-RG, COPPETEC Foundation, Rio de Janeiro. http://dx.doi.org10.1016/10.1023/A:1010954118066

ReVelle, C. S., \& Eiselt, H. A. (2005). Location analysis: A synthesis and survey. Eur J Oper Res, 165(1), 1-19. http://dx.doi.org10.1016/10.1016/j.ejor.2003.11.032 
Şahin, G., \& Süral, H. (2007). A review of hierarchical facility location models. Comp Oper Res, 34(8), 2310-2331. http://dx.doi.org10.1016/10.1016/j.cor.2005.09.005

Samorani, M. (2013). The wind farm layout optimization problem. In: Handb of Wind Power Syst Springer Berlin Heidelberg, pp 21-38. Retrived from http://dx.doi.org/10.1007/978-3-642-41080-2_2

Santner, T. J., Williams, B. J., \& Notz, W. I. (2003). The Design and Analysis of Computer Experiments. New York: Springer Verlag.

Simpson, T. W., Lin, D. K., \& Chen, W. (2001). Sampling strategies for computer experiments: design and analysis. Int J RelAppl, 2(3), 209-240.

SI-Ocean. (2012). Ocean Energy: State of the Art. Retrived from http://www.si-ocean.eu/en/Technology-Assessment/Technology-Status/

Stanimirović, I. P. (2013). Successive computation of some efficient locations of the Weber problem with barriers. J Appl Math Comp, 42(1-2), 193-211. http://dx.doi.org/10.1007/s12190-012-0637-x

Sun, X. (2008). Numerical and experimental investigation of tidal current energy extraction. Ph.D. Thesis University of Edinburgh, UK. Retrived from http://hdl.handle.net/1842/2756

Terouhid, S. A., Ries, R., \& Fard, M. M. (2012). Towards sustainable facility location: A literature review. J Sust Dev, 5(7), 18-34. http://dx.doi.org/10.5539/jsd.v5n7p18

Thomson, J., Polagye, B., Durgesh, V., \& Richmond, M. C. (2012). Measurements of turbulence at two tidal energy sites in Puget Sound, WA. IEEE J Oceanic Engin, 37(3), 363-374. http://dx.doi.org/10.1109/JOE.2012.2191656

Topal, E., \& Ramazan, S. (2010). A new MIP model for mine equipment scheduling by minimizing maintenance cost. Eur J Oper Res, 207, 1065-1071. http://dx.doi.org/10.1016/j.ejor.2010.05.037

Turner, S. D. O., Romero, D. A., Zhang, P. Y., Amon, C. H., \& Chan, T. C. Y. (2014). A new mathematical programming approach to optimize wind farm layouts. Renew Energ, 63(3), 674-680. http://dx.doi.org/10.1016/j.renene.2013.10.023

Turnock, S. R., Phillips, A. B., Banks, J., \& Nicholls-Lee, R. (2011). Modelling tidal current turbine wakes using a coupled RANS-BEMT approach as a tool for analysing power capture of arrays of turbines. Ocean Engin, 38, 1300-1307. http://dx.doi.org/10.1016/j.oceaneng.2011.05.018

Vennell, R. (2010). Tuning turbines in a tidal channel. J Fluid Mech, 663, 253-267. http://dx.doi.org/10.1017/S0022112010003502

Vennell, R. (2011). Tuning tidal turbines in-concert to maximise farm efficiency. $J$ of Fluid Mech, 671, 587-604. http://dx.doi.org/10.1017/S0022112010006191

Vennell, R. (2012). Realizing the potential of tidal currents and the efficiency of turbine 
farms in a channel. Renew Energ, 47(11), 95-102. http://dx.doi.org/10.1016/j.renene.2012.03.036

Vennell, R. (2013). Exceeding the Betz limit with tidal turbines. Renew Ener, 55, 277-285. http://dx.doi.org/10.1016/j.renene.2012.12.016

Wang, G. G., \& Shan, S. (2007). Review of metamodeling techniques in support of engineering design optimization. $J$ Mech Des, 129(4), 370-380. http://dx.doi.org/10.1115/1.2429697

Wang, Y., Duan, M., Xu, M., Wang, D., \& Feng, W. (2012). A mathematical model for subsea wells partition in the layout of cluster manifolds. Appl Ocean Res, 36, 26-35. http://dx.doi.org/10.1016/j.apor.2012.02.002

Xu, M., \& Zhuan, X. (2013). Optimal planning for wind power capacity in an electric power system. Renew Energ, 53, 280-286. http://dx.doi.org/10.1016/j.renene.2012.11.015

Yilmaz, B., \& Dağderviren, M. (2011). A combined approach for equipment selection: F-PROMETHEE method and zero-one goal programming. Expert Sys Appl, 38, 11641-11650.

\section{Glossary}

$a-$ axial induction factor [-].

$C_{P}-$ power coefficient [-].

$D$ - rotor diameter $[\mathrm{m}]$.

$\mathbf{E}$ - edges [m].

$f_{0}$ - objective function [-].

$f_{i}-$ constraint functions [-].

$F_{t}-$ constraint functions [-].

G - fluid field [-].

$h$ - depth of water from chart datum [m].

$H$ - water-column height [m].

$N F$ - number of rows of turbines in the farm [-].

$N T$ - number of turbines in the whole farm [-].

NTR1 - number of turbines in the first row [-].

$P_{t v}$ - turbine type t power output generated at vertex v [MW].

$R_{v}$ - region where a turbine cannot be placed due to geometric interference [-].

$R^{2}$ - coefficient of fitness [-]. 
$S_{v}-$ region where a turbine cannot be placed due to hydrodynamic interference [-].

$t$ - index for turbine type [-].

$\mathbf{T}-$ set of turbine types [-].

$U-$ flow velocity $\left[\mathrm{m} . \mathrm{s}^{-1}\right]$.

$U_{d}$ - flow velocity at turbine's rotor $\left[\mathrm{m} \cdot \mathrm{s}^{-1}\right]$.

$U_{0}$ - incident flow velocity $\left[\mathrm{m} . \mathrm{s}^{-1}\right]$.

$U_{50}$ - flow velocity for at least $50 \%$ of the time $\left[\mathrm{ms}^{-1}\right]$.

$v-\operatorname{vertex}[-]$.

$\mathbf{V}-$ set of vertices [-].

$y$ - computer simulation response [-].

$\hat{y}$ - predicted simulation response [-].

$\bar{y}$ - mean of observed data [-].

$\mathbf{y}-$ location vector $[\mathrm{m}]$.

$X_{t v}-$ binary variable $\{0,1\}$.

$\mathbf{x}$ - design variable vector [-].

$x_{1}-$ longitudinal spacing design variable $[\mathrm{m}]$.

$x_{2}$ - lateral spacing design variable $[\mathrm{m}]$.

$\widehat{\beta}$ - polynomial parameters [-].

$\zeta$ - water surface elevation $[\mathrm{m}]$.

$\rho$ - sea water density $\left[\mathrm{kg} \cdot \mathrm{m}^{-3}\right]$.

\section{Copyright Disclaimer}

Copyright for this article is retained by the author(s), with first publication rights granted to the journal.

This is an open-access article distributed under the terms and conditions of the Creative Commons Attribution license (http://creativecommons.org/licenses/by/3.0/). 